\title{
DICTATION SOFTWARE DEVELOPMENT AND ITS APPLICATION
}

\section{Radmila Suzić*, Ivan Radosavljević}

\section{Singidunum University,} Belgrade, Serbia

\begin{abstract}
:
The aim of this paper is to present a new digital tool for writing dictation which can be used as an effective teaching technique in English language classes because it creates an optimal learning environment in the digital age. The first part of the paper provides an overview of theoretical interpretations on the importance of using the dictation as a writing technique in foreign language classes, after which a new digital solution is presented. The presented digital platform for dictation writing allows users, both students and teachers, to install and use this feature without additional complications. The new platform is implemented in Python using the Flask web application framework, and it provides a single interface through which users can access and manipulate dictation related entities. Teachers can perform CRUD operations for entities such as students, groups, dictations, submissions. The automatic grading is implemented in this platform by utilizing the longest common sequence algorithm to compare the original dictation transcript with the student submitted text. In that way grading is done automatically, providing complete objectivity without the need to manually search for errors within each submission. The advantage of this platform is seen in the fact that traditional language learning techniques are being modernised and thus completely integrated in the new digital teaching era.
\end{abstract}

Keywords:

Dictation, language learning, software development.

\section{INTRODUCTION}

As a result of school closures due to the global Covid 19 pandemic, digital distance learning, where technologically possible, has been taking a major role. Therefore, teachers and students are using digital platforms, applications and contents, all with the aim of adapting teaching and learning strategies to this, relatively new learning environment [1]. Since teaching English as a foreign language is based on teaching the language through four language skill - listening, speaking, reading and writing, many teachers experienced a problem with the implementation of the writing technique - dictation in an online environment. Dictation as a writing technique is of extreme importance for foreign language learners of all level, since it affects the development of other language
Correspondence:

Radmila Suzić

e-mail:

rsuzic@singidunum.ac.rs 
skills such as listening, speaking and of course writing $[2,3,4]$. Thus, the need to create a way to implement this writing technique in online teaching led to the creation of the new dictation software whose development and application in teaching will be explained in detail.

\section{RELATED WORK}

There are numerous platforms that can be used to conduct the dictation in an online environment, but detailed analyses of the same reveal a number of shortcomings that make them impractical for further use in a classroom situation. Most of these platforms are based on the idea of converting text to speech, which is a technologically advanced alternative for reading text out loud in situations when the teacher is absent $[5,6,7]$; however, it is rather inconvenient to be used as a platform for conducting a writing activity such as dictation since the reading is continuous and has no characteristics of the traditional dictation reading (the example of such platforms are: Natural readers ${ }^{1}$ and From text to speech $^{2}$ ). On the other hand, there are platforms such as Speechling ${ }^{3}$, DailyDictation ${ }^{4}$, and Listen and Write ${ }^{5}$ that allow users to control the speed of dictation, insert the text for dictation and see corrections immediately after the dictation is completed; however, the limitations of these platforms are reflected in the inability of the teacher to see students' results - since these platforms' primary function is to support independent language learning outside of the classroom situation.

Another thing regarding existent online platforms for dictation writing is the lack of the possibility of repeating individual phrases or semantic units, which is an important characteristic of traditional dictation writing [8]. Reading and repeating individual phrases and/or sematic units is extremely valuable in language learning because of idioms and similes that should be herd and learned as a whole [9], thus, repeating them enhances students' ability to remember them in such a way. Due to all of that, the need for development of new dictation platform was needed in order to continue using dictation as a language learning tool in online teaching environment.

\section{IMPLEMENTATION DETAILS}

Since the dictation platform is intended to be used by users of various skill levels the solution had to be available on most devices without the need to perform any special configuration or installation procedures. Thus, the solution presented in this paper is implemented as a web application. The backend of the web application is implemented in Python [10] using the Flask web application framework [11], whilst the frontend is implemented using the Angular framework [12] and Angular Material UI components library [13]. The solution provides a single interface through which the users, teachers and students, can access and manipulate dictation related entities. The entities that can be manipulated through the web application are students, dictations and submissions. Teachers can add, edit and remove all of the aforementioned entities. Figure 1 shows a class diagram of the entities available in the web application. As can be seen on the diagram, each student can be assigned to one or more groups. These groups can represent skill levels, study groups or any other criteria by which students should be segregated. Dictations also have an assigned group. This allows for dictations to be delivered to the students of the corresponding group only. Additionally, dictations contain the original transcript which can be used to automatically grade student submissions. Each student submission is described by the Submission class. Instances of this class are created automatically when a student access the dictations for the first time. Once the student submits his dictation the existing instance of the submission is updated to contain their answer. Submission instances are also used to track the time at which the students have started the dictations, as well as due time and time at which the students have submitted their answers. Furthermore, the Submission stores the score, which can be assigned automatically upon dictation submission or afterwards manually by the teacher. The creation and submission IP addresses are also stored in the Submission instances. These can be used to verify that the same student commenced and submitted the dictation.

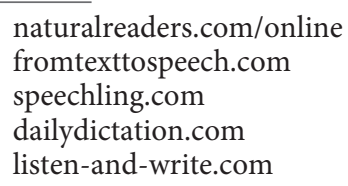




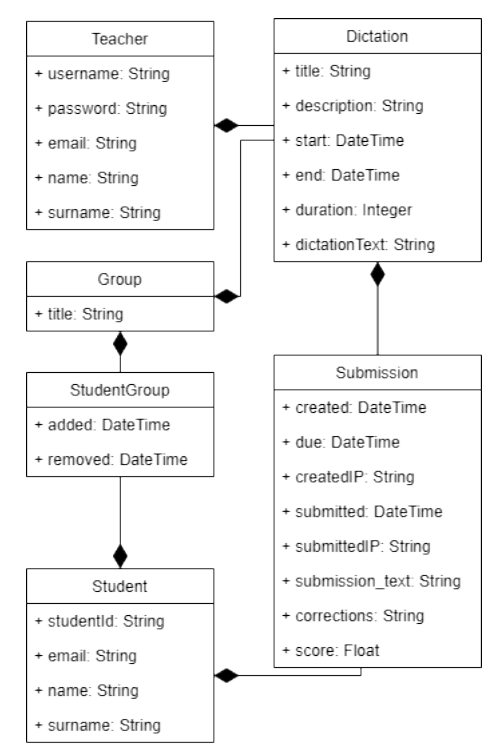

Figure 1 - Dictation software class diagram

The automatic grading is implemented by utilizing the longest common sequence algorithm to compare the original dictation transcript with the student submitted text. If the algorithm returns a result indicating that less than $10 \%$ of the student submitted text must be changed in order to equal the original transcript the submission score is set to "passed" i.e., to a numeric value of 1 , otherwise the score is set to 0 . Additionally, upon automatic grading, all of the necessary corrections are stored in the submission instance. Although this grading scheme is very rudimentary it effectively reduces the time that teachers have to spend grading the students manually. Furthermore, storage of the corrections allow teachers to easily review any student submission and to grade them in any desired way without the need to manually search for errors within each submission.

The user interface of the application can be divided into two major components the teacher panel and the student panel. The teacher panel is accessed by logging in through the teacher panel login page show in Fig 2. The home page of the teacher panel, shown in Fig 3, presents the teacher with a form for creating new dictations and a table of all of the currently available dictations. Each dictation shown in the table can be deleted or their details can be requested.

\section{Prijava na sistem}

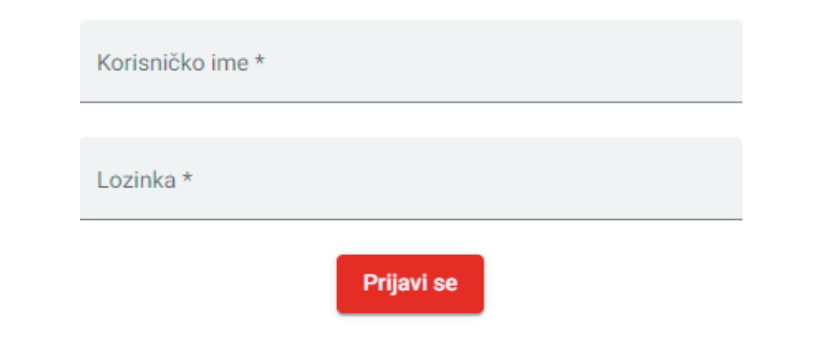

Figure 2 - Teacher login screen

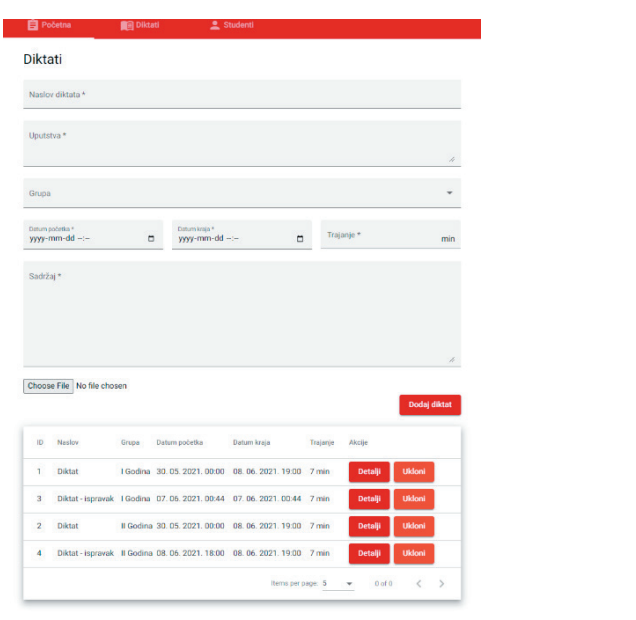

Figure 3 - Teacher panel home screen

Figure 4 shows a page displaying details of a single dictation. At the top of the page is a form that contains all of the dictation data. This form can be used to edit any of the dictation data displayed within it. Below the form is a table displaying all of the submissions made for the viewed dictation. Each submission can be deleted or its details accessed by clicking a corresponding action button.

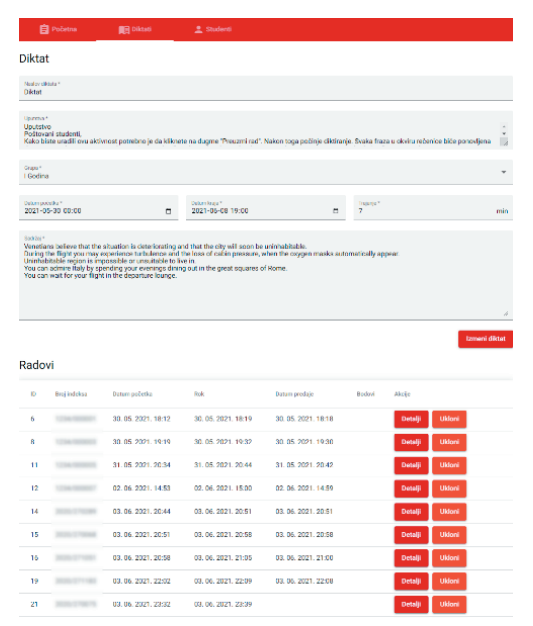

Figure 4 - Dictation details page 
A submission details page, shown in Fig 5, contains data about the original dictation, the student who created the submission and the submission itself. On this page the teacher can edit the submission's due time, if the submission is not already expired and set the score for the submission.

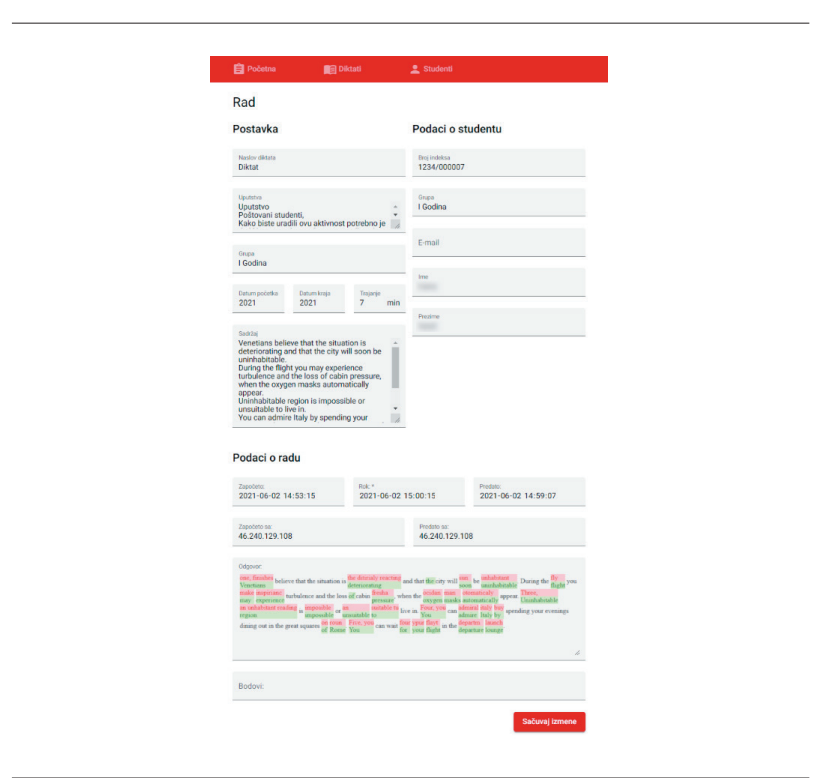

Figure 5 - Submission details page

A page to register and view all of the registered students is shown in Fig 6. The form at the top of the page is used to register new students while the table below shows all of the already registered students. Each registered student can be deleted, and their details can be access through the actions available in the table. The page displaying student details, Fig 7, contains a form used to display and edit student details and a table showing all of the submissions made by the student whose details are viewed.

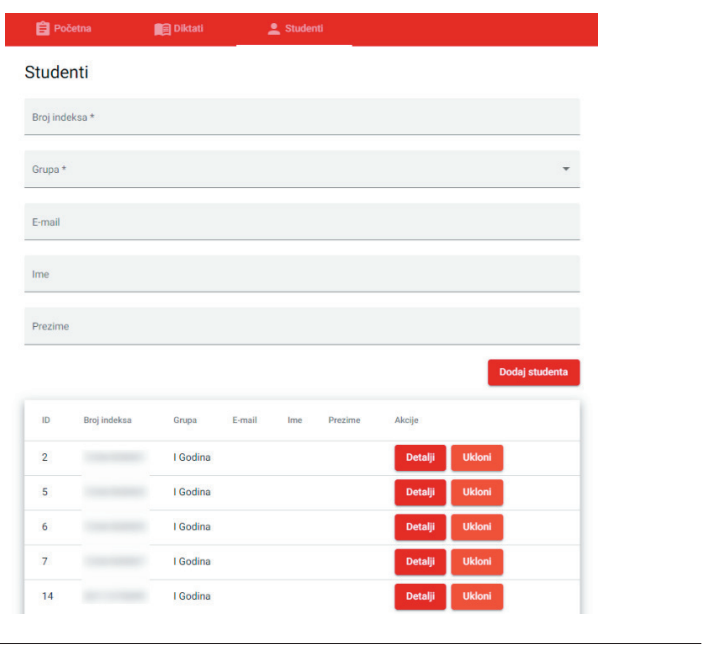

Figure 6 - Teacher panel students page

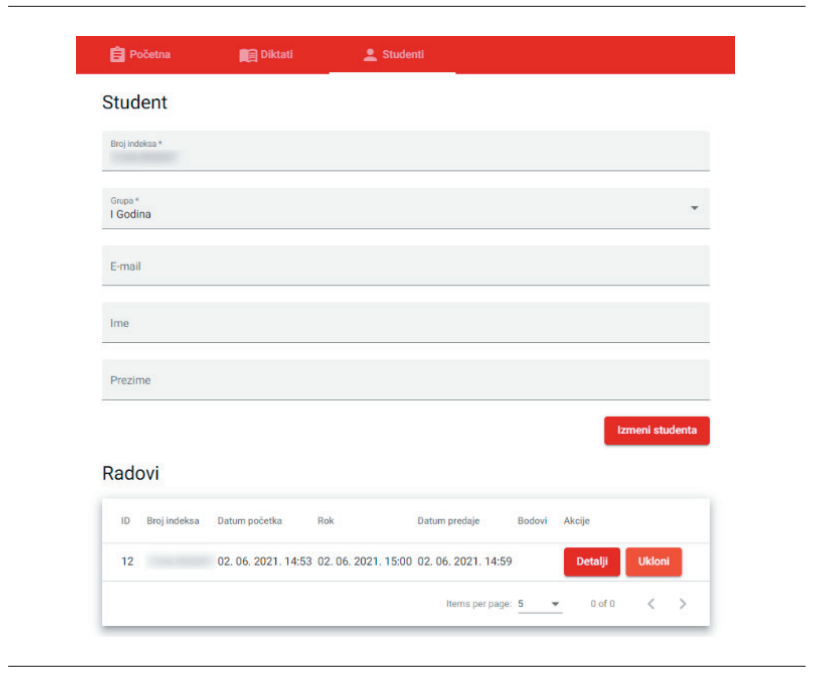

Figure 7 - Student details page

Similarly to the teacher panel, the student panel is accessed by first logging in through the student panel login page shown in Fig 8. The home page of the student panel shows a table of all the dictations available to the logged in student at the time of accessing the student panel. This page is shown in Fig 9.

\section{Prijava na sistem}

Broj indeksa: GGGG/BBBBBB *

\section{Prijavi se}

Figure 8 - Student login page

\section{自 Poóetra 立 ocene}

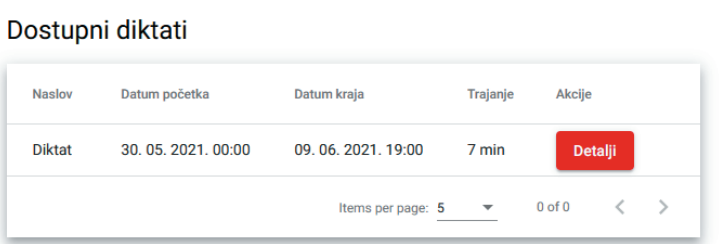

Figure 9 - Student panel home page 
By clicking the details button next to each dictation, the student is shown a page containing the information about the start, end, duration, and dictations instructions. In case that the student has not already commenced the dictation, a button to create new submission is shown at the bottom of the page, Fig 10. Upon clicking this button a new submission is created, the dictation recording is automatically played, and the page is updated to show the time at which the submission was created, due time, and remaining time. Also, a button to pause and play the dictation, a progress bar showing the remaining dictation time, an input field to enter the dictation transcript, and a submission button are added to the page. An example of this page is shown in Fig 11.

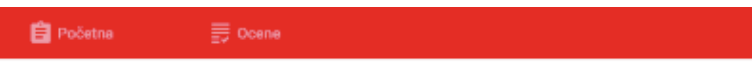

\section{Diktat}

Dostupno od 30. 05. 2021. 00:00

do 09. 06. 2021. 19:00

Vreme izrade: $7 \mathrm{~min}$

Zadatak nije preuzet

\section{Uputstvo:}

Uputstvo

Poštovani studenti,

Kako biste uradili ovu aktivnost potrebno je da kliknete na dugme 'Preuzmi rad". akon toga počinje diktiranje. Svaka fraza u okviru rečenice biće ponovljena dva puta. U toku pisanja moguce je raditi pojedinačne slovne korekcije ali je

kopiranje, ubacivanje i izmena prethodnih reči onemogucena.

Nakon diktata potrebno je popuniti i kraću anketu koja je anonimna

Srećnol

Preuzmi zadatak

Figure 10 - Dictation before being activated by the student

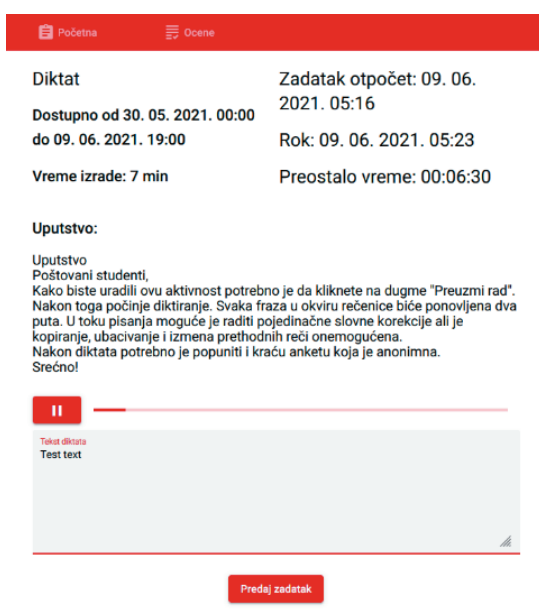

Figure 11 - Dictation after being activated by the student
Besides pages showing the available dictations and dictation details, the logged in student can access a page showing a table of their previous submission, Fig 12. This page allows students to view their grades once they submit their dictations.

\section{E Početna $\quad \equiv$ Ocene}

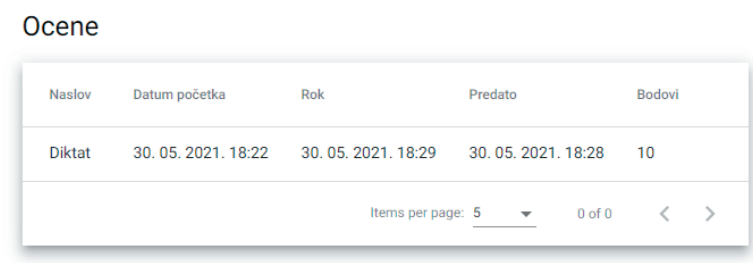

Figure 12 - Student's grades page

\section{CONCLUSION}

The relevance of this paper lies in the fact that the traditional language teaching techniques that have been used for years in foreign language classes can be used in the new digital environment in an almost unchanged form. The fact is that we are entering an era of new, digital humanities that, given the changes in society and the education system, require results that are precise, accurate, fast and digital [14]. Therefore, the previously presented platform for writing dictation is a new intelligent learning system whose importance is reflected in the simple implementation in the process of traditional teaching.

The most important advantage of using this digital tool in traditional language teaching is reflected in the fact that it improves the quality of work of both teachers and students.

Students are given the opportunity to do dictation assignments not only in class, but also as a form of additional practice at home; the presented platform allows them to repeat, revise and write down the newly learned words and phrases, completely independently. This type of dictation practice has so far been possible only with the help of teachers, friends or parents who would dictate texts to students, but correcting them would take time, so this activity was often neglected in independent work at home. The implementation of the technique of writing dictation in digital form enables students not only to independently practice texts processed in class in a new, modern environment, but they simultaneously practice typing skill - a skill which is the necessity of the 
digital era. The feedback is received momentarily after they submit their task, which is another of the characteristics of the digital age, which at same time enables them to register their own progress in the form of self-evaluation [15].

As for the benefits for teachers, they are also numerous. Tasks once entered on this platform are always easily accessible, reducing the time spent on their creation, editing, recording. The assessment is objective, accurate and precise with the possibility of a detailed analysis of each error in the work. The use of digital tools of this type in teaching allows the teacher to take into account the individual needs of students, because at the same time the teacher can play several different versions of dictation, where the volume of text, complexity of written words, reading speed and number of repetitions can be completely adjusted to individual needs of students.

This platform can also be used as an assessment tool, with immediate feedback.

\section{REFERENCES}

[1] D. M. Sandeep, "Increasing use of digital platforms for online teaching- learning in COVID Era: Pros and cons," p. 5.

[2] G. Kavaliauskienè and L. Anusiene, "Online Tool to Improve Language Proficiency," Coactivity: Philology, Educology / Santalka: Filologija, Edukologija, vol. 19, p. 31-37, 2011.

[3] D. Ljubojević, "Primena diktata u nastavi engleskog jezika na ranom uzrastu," Inovacije u nastavi časopis za savremenu nastavu, vol. 23, p. 72-79, 2010.

[4] The Effectiveness of Dictation Method in College English Vocabulary Teaching | Semantic Scholar, 2021.

[5] G. Eksi and S. Yesilcinar, "An Investigation of the Effectiveness of Online Text-to-Speech Tools in Improving EFL Teacher Trainees' Pronunciation," English Language Teaching, vol. 9, p. p205, 2016.

[6] Q. Tang, "The Effectiveness of Dictation Method in College English Vocabulary Teaching," 2012.

[7] H.-H. Chiang, "A Comparison Between TeacherLed and Online Text-to-Speech Dictation for Students' Vocabulary Performance," English Language Teaching, vol. 12, p. 77, 2019.

[8] Alkire - Dictation as a Language Learning Device (TESL/TEFL), 2021.

[9] J. I. Liontas, "Why Teach Idioms? A Challenge to the Profession," p. 21, 2017.
[10] Welcome to Python.org, 2021.

[11] Welcome to Flask - Flask Documentation (2.0.x), 2021.

[12] Angular, 2021.

[13] Angular Material, 2021.

[14] L. V. Guseva, E. V. Koroleva, G. A. Kruchinina, J. A. Marinina, A. A. Oladyshkina, E. G. Popkova and B. S. Sergi, "Digital Humanities: The Possibility of Using Intelligent Learning Systems in Teaching Foreign Languages," 2020.

[15] M. Badran, "Digital Tools and Language Learning," p. 49. 